\title{
PERTUMBUHAN DAN HASIL BAWANG DAUN \\ (Allium fistulosum L.) VARIETAS LINDA \\ AKIBAT PEMBERIAN PUPUK KANDANG AYAM \\ DAN PUPUK UREA
}

\section{GROWTH AND YIELD OF SPRING ONION (Allium fistulosum L.) LINDA VARIETY DUE TO CHICKEN MANURE AND UREA FERTILIZER}

\author{
Yudi Yusdian ${ }^{1)}$, Merry Antaralina ${ }^{1)}$, Ahmad Diki ${ }^{2)}$ \\ ${ }^{1)}$ Fakultas Pertanian Universitas Bale Bandung \\ 2) Alumni Fakultas Pertanian Universitas Bale Bandung \\ Korespondensi : yyudiyusdian@yahoo.com
}

Diterima 23 Maret 2016 / Disetujui 28 Juni 2016

\begin{abstract}
ABSTRAK
Penelitian ini bertujuan untuk mengetahui pengaruh kombinasi pupuk kandang ayam dan pupuk urea terhadap pertumbuhan dan hasil bawang daun. Penelitian dilaksanakan di kampung Legokkaso Desa Cinanggela Kecamatan Pacet Kabupaten Bandung Provinsi Jawa Barat. dengan jenis tanah Latosol dengan $\mathrm{pH}$ 5,7, terletak pada ketinggian $1.200 \mathrm{~m}$ di atas permukaan laut. Curah hujan 2.205 mm/tahun termasuk curah hujan tipe C3 (Oldeman, 1979). Percobaan dilaksanakan dari bulan Maret sampai dengan bulan Mei 2014. Metode penelitian yang digunakan adalah metode Rancangan Acak Kelompok (RAK) yang terdiri dari 6 perlakuan dan 4 ulangan. Perlakuan kombinasi pupuk kandang ayam dan pupuk urea adalah sebagai berikut: A $(0 \mathrm{~g}+2,2 \mathrm{~g}), \mathrm{B}(12 \mathrm{~g}+2,0 \mathrm{~g}), \mathrm{C}(14 \mathrm{~g}+1,8 \mathrm{~g}), \mathrm{D}(16 \mathrm{~g}+1,6 \mathrm{~g}), \mathrm{E}(18 \mathrm{~g}+1,4 \mathrm{~g}), \mathrm{F}(20 \mathrm{~g}+0 \mathrm{~g})$. Hasil analisis menunjukkan bahwa pemberian dosis $16 \mathrm{~g}$ pupuk kandang ayam dan 1,6 g pupuk urea memberikan pengaruh yang lebih baik terhadap pertumbuhan tinggi tanaman, jumlah anakan, dan hasil per tanaman bawang daun varietas Linda.
\end{abstract}

Kata kunci: Bawang Daun Var. Linda, Pupuk Kandang Ayam, Urea

\begin{abstract}
This study aimed to determine the effect of chicken manure and urea dosage combination on the growth and yield of spring onions. The experiment was conducted in the Legokkaso Residential, Cinanggela Village, Pacet Subdistrict, Bandung Regency, of West Java Province. The soil was Latosol with $\mathrm{pH}$ 5.7, located at an altitude of 1,200 m above sea level. Rainfall was $2.205 \mathrm{~mm} /$ years including precipitation C3 type (Oldeman, 1979). The experiment was conducted from March to May 2014. The research method used was randomized block design method (RBD) consisting of 6 treatments and 4 replications. The treatment was combination of chicken manure and urea as follows: A $(0 \mathrm{~g}+2,2 \mathrm{~g}), \mathrm{B}(12 \mathrm{~g}+2,0 \mathrm{~g}), \mathrm{C}(14 \mathrm{~g}+1,8 \mathrm{~g}), \mathrm{D}(16 \mathrm{~g}+1,6 \mathrm{~g})$, $\mathrm{E}(18 \mathrm{~g}+1,4 \mathrm{~g}), \mathrm{F}(20 \mathrm{~g}+0 \mathrm{~g})$. The result showed that dosage $16 \mathrm{~g}$ of chicken manure and $1.6 \mathrm{~g}$ urea gave a better effect on the growth of plant height, number of tillers, yield of plant.
\end{abstract}

Keywords: Chicken Manure, Spring Onion Var. Linda, Urea 


\section{PENDAHULUAN}

Bawang daun (Allium fistulosum L.) merupakan salah satu komoditas tanaman hortikultura yang layak dikembangkan secara intensif di kabupaten Bandung Jawa Barat khususnya dan Indonesia pada umumnya, selain digunakan sebagai bahan penyedap rasa (bumbu) dan bahan campuran berbagai makanan populer di Indonesia.

Luas areal panen bawang daun di Indonesia setiap tahun terus meningkat, karena prospek pemasaran komoditas ini menunjukkan kecenderungan yang semakin baik. Pemasaran produksi bawang daun segar tidak hanya untuk pasar dalam negeri (domestik) melainkan juga pasar luar negeri (ekspor). Badan Pusat Statistik (BPS) tahun 2013 luasan areal, produksi dan produktivitas bawang daun di Jawa Barat dari tahun 2009 sampai dengan 2013 terus mengalami peningkatan pada produksi dan produktivitas bawang daun sedangkan pada luasan areal pertanian bawang daun mengalami penurunan. Pada tahun 2009 luasan areal pertanian bawang daun di Jawa Barat yaitu 14.455 ha dengan produksi 200.028 ton dan produktivitasnya 13,84 ton $\mathrm{ha}^{-1}$ mengalami peningkatan di tahun 2013 menjadi 184.539 ton untuk produksi dengan produktivitas 14,20 ton $\mathrm{ha}^{-1}$ dan mengalami pengurangan pada luasan areal di tahun 2013 menjadi 12.994 ha (BPS, 2013).

Bawang daun memiliki nilai ekonomis yang cukup penting. Prospek bawang daun cukup baik untuk pemenuhan konsumen domestik dan untuk permintaan ekspor. Pada saat ini produktivitas di tingkat petani masih rendah akibat belum menggunakan media tanam dan pupuk yang belum optimal. Untuk memenuhi permintaan pasar dalam jumlah yang banyak maka produksi bawang daun harus ditingkatkan melalui budidaya yang intensif. Budidaya yang intensif diantaranya menggunakan media tanam dan pemberian pupuk yang berimbang.

Bawang daun dapat tumbuh dengan optimal jika struktur tanah mendukung, yaitu dengan tersedianya nutrisi atau unsur hara yang dibutuhkan tanaman. Pemberian pupuk kandang (pukan) ayam, kambing atau sapi dapat memperbaiki struktur tanah dan mendorong perkembangan populasi mikroorganisme tanah. Rendahnya bahan organik dalam tanah akan menyebabkan pencucian unsur hara sehingga tidak tersedia bagi tanaman (Brady, 1997). Pupuk organik memiliki kandungan unsur hara yang lebih rendah dibanding pupuk anorganik, oleh karena itu untuk meningkatkan produksi bawang daun diperlukan pemberian kombinasi pupuk organik dan anorganik yang seimbang.

Menurut Laude dan Tambing (2010) Pemupukan merupakan salah satu cara yang dapat dilakukan untuk memenuhi ketersediaan unsur hara tanah yang dibutuhkan oleh bawang daun, tanaman bawang daun memerlukan pupuk yang banyak mengandung unsur $\mathrm{N}$ untuk memaksimalkan pertumbuhan daun. Pupuk kandang yang berasal dari kotoran ayam sangat tinggi kandungan unsur $\mathrm{N}$ $(2,71 \%)$, dibandingkan pupuk yang berasal dari kotoran hewan lainnya.

Laude dan Tambing (2010) menyatakan bahwa dosis pupuk kandang ayam dengan dosis 12 ton ha ${ }^{-1}$ memberikan hasil tertinggi pada parameter pengamatan tinggi tanaman dan berat segar tanaman. Menurut Bertua, Irianto dan Ardiyaningsih (2012) dosis pupuk kandang ayam 10 ton 
ha $^{-1}$ memberikan hasil terbaik pada jumlah buah dan bobot buah pertanaman. Hasi penelitian Susantidiana (2011) perlakuan dosis Urea $1,8 \mathrm{~g}$ per tanaman merupakan perlakuan terbaik dalam meningkatkan pertumbuhan dan produksi bawang daun.

Nitrogen diserap tanaman dalam bentuk ion nitrat $\left(\mathrm{NO}_{3}\right)$ dan ion ammonium $\left(\mathrm{NH}_{4}{ }^{+}\right)$. Nitrogen dibutuhkan untuk membentuk senyawa penting seperti klorofil, asam nukleat dan enzim, karena itu $\mathrm{N}$ dibutuhkan dalam jumlah relatif besar pada setiap pertumbuhan tanaman, khususnya pada pertumbuhan vegetatif. Sebaliknya, jika tanaman kekurangan unsur $\mathrm{N}$ maka akan terjadi gejala seperti warna daun pucat kekuningan, pertumbuhan tanaman lambat dan kerdil, dalam keadaan kekurangan yang parah daun menjadi kering dimulai dari bagian bawah tanaman terus ke bagian atas tanaman.

\section{BAHAN DAN METODE PENELITIAN}

Penelitian ini dilaksanakan di kampung Legokkaso Desa Cinanggela Kecamatan Pacet Kabupaten Bandung Provinsi Jawa Barat, dengan jenis tanah Latosol dan $\mathrm{pH}$ 5,7 (lampiran 3) terletak pada ketinggian $1.200 \mathrm{~m}$ di atas permukaan laut. Curah hujan $2.205 \mathrm{~mm}$ tahun $^{-1}$ termasuk curah hujan tipe C-3 menurut (Oldeman, 1979). Percobaan dilaksanakan dari bulan Maret sampai dengan bulan Mei 2014.

Bahan-bahan yang digunakan dalam percobaaan ini adalah bibit bawang daun (Allium fistullosum L.) varietas Linda, pupuk kandang ayam, Urea sebagai sumber $\mathrm{N}$, fungisida Rampart dan insektisida Bionik. Alat-alat yang digunakan dalam penelitian ini adalah cangkul, sabit, papan merk atau nomor, tali, timbangan, gunting, alat ukur, penggaris, dan alat tulis.

Metode penelitian yang digunakan adalah metode Rancangan Acak Kelompok (RAK) yang terdiri dari 6 perlakuan dan 4 ulangan, jumlah tanaman per plot 6 buah termasuk 4 tanaman sebagai sampel, sehingga jumlah tanaman keseluruhan adalah 144 tanaman.

Tabel 1. Notasi Kombinasi Perlakuan

\begin{tabular}{ccc}
\hline \multirow{2}{*}{$\begin{array}{c}\text { Notasi } \\
\text { Perlakuan }\end{array}$} & \multicolumn{2}{c}{$\begin{array}{c}\text { Kombinasi Dosis Pupuk } \\
\text { per Tanaman }\end{array}$} \\
\cline { 2 - 3 } & $\begin{array}{c}\text { Kandang } \\
\text { ayam }\end{array}$ & Urea \\
\hline A & 0 & 2,2 \\
B & 12 & 2,0 \\
C & 14 & 1,8 \\
D & 16 & 1,6 \\
E & 18 & 1,4 \\
F & 20 & 0 \\
\hline
\end{tabular}

\section{HASIL DAN PEMBAHASAN}

Pengamatan yang dilakukan terdiri dari: variabel tinggi tanaman, jumlah anakan, hasil per tanaman. Uraian dari tiap variabel tersebut akan ditampilkan dibawah ini.

Pada Tabel 2, 3 dan 4 perlakuan D (16 g pukan ayam dan 1,6 g Urea) menunjukkan pengaruh yang lebih baik terhadap tinggi tanaman, jumlah anakan dan hasil per tanaman dibandingkan dengan perlakuan $A$ (0 g pukan ayam dan 2,2 g Urea), B (12 g pukan ayam dan 2,0 g Urea), C (14 g pukan ayam dan 1,8 g Urea), E (18 g pukan ayam dan $1,4 \mathrm{~g}$ Urea) dan perlakuan $\mathrm{F}(20 \mathrm{~g}$ pukan ayam dan $0 \mathrm{~g}$ Urea). 


\section{Tinggi Tanaman $(\mathrm{cm})$}

Tabel 2. Pengaruh Kombinasi Dosis Pupuk Kandang Ayam dan Pupuk Urea terhadap Rata-rata Tinggi Tanaman (cm) Pada Umur 4, 6, 8 dan 10 MST.

\begin{tabular}{ccccc}
\hline \multirow{2}{*}{ Perlakuan } & \multicolumn{4}{c}{ Rata-Rata Tinggi Tanaman } \\
\cline { 2 - 5 } & $4 \mathrm{MST}$ & $6 \mathrm{MST}$ & $8 \mathrm{MST}$ & $10 \mathrm{MST}$ \\
\hline $\mathrm{A}$ & $24 \mathrm{a}$ & $28 \mathrm{a}$ & $32 \mathrm{a}$ & $37 \mathrm{a}$ \\
B & $27 \mathrm{a}$ & $31 \mathrm{ab}$ & $35 \mathrm{ab}$ & $39 \mathrm{a}$ \\
$\mathrm{C}$ & $25 \mathrm{a}$ & $28 \mathrm{a}$ & $32 \mathrm{a}$ & $37 \mathrm{a}$ \\
D & $27 \mathrm{a}$ & $33 \mathrm{~b}$ & $38 \mathrm{~b}$ & $44 \mathrm{~b}$ \\
E & $25 \mathrm{a}$ & $31 \mathrm{ab}$ & $36 \mathrm{~b}$ & $40 \mathrm{a}$ \\
F & $26 \mathrm{a}$ & $31 \mathrm{ab}$ & $36 \mathrm{~b}$ & $39 \mathrm{a}$ \\
\hline
\end{tabular}

Keterangan : - Angka rata-rata yang diikuti oleh huruf yang sama pada kolom yang sama menunjukkan hasil yang tidak berbeda nyata menurut Uji Jarak Berganda Duncan pada taraf $5 \%$.

- MST = Minggu Setelah Tanam.

\section{Jumlah Anakan}

Tabel 3. Pengaruh Kombinasi Dosis Pupuk Kandang Ayam dan Pupuk Urea terhadap Rata-rata Jumlah Anakan Pada Umur 4, 6, 8 dan 10 MST.

\begin{tabular}{crccc}
\hline \multirow{2}{*}{ Perlakuan } & \multicolumn{4}{c}{ Rata-Rata Jumlah Anakan } \\
\cline { 2 - 5 } & $4 \mathrm{MST}$ & $6 \mathrm{MST}$ & $8 \mathrm{MST}$ & $10 \mathrm{MST}$ \\
\hline $\mathrm{A}$ & $4 \mathrm{a}$ & $5 \mathrm{a}$ & $7 \mathrm{a}$ & $8 \mathrm{a}$ \\
B & $4 \mathrm{a}$ & $5 \mathrm{a}$ & $7 \mathrm{a}$ & $8 \mathrm{a}$ \\
C & $4 \mathrm{a}$ & $5 \mathrm{a}$ & $7 \mathrm{a}$ & $8 \mathrm{a}$ \\
D & $4 \mathrm{a}$ & $6 \mathrm{~b}$ & $8 \mathrm{~b}$ & $11 \mathrm{~b}$ \\
E & $4 \mathrm{a}$ & $7 \mathrm{a}$ & $7 \mathrm{a}$ & $9 \mathrm{a}$ \\
F & $4 \mathrm{a}$ & $7 \mathrm{a}$ & $7 \mathrm{a}$ & $9 \mathrm{a}$ \\
\hline
\end{tabular}

Keterangan : - Angka rata-rata yang diikuti oleh huruf yang sama pada kolom yang sama menunjukkan hasil yang tidak berbeda nyata menurut Uji Jarak Berganda Duncan pada taraf $5 \%$.

- MST = Minggu Setelah Tanam.

\section{Hasil Per Tanaman}

Tabel 4. Pengaruh Kombinasi Dosis Pupuk Kandang Ayam dan Pupuk Urea terhadap Rata-rata Hasil Per Pertanaman Pada Umur 10 MST.

\begin{tabular}{cc}
\hline \multirow{2}{*}{ Perlakuan } & $\begin{array}{c}\text { Rata-Rata Hasil per } \\
\text { Tanaman }\end{array}$ \\
\cline { 2 - 2 } & 10 MST \\
\hline A & -- -- \\
B & $207 \mathrm{a}$ \\
C & $382 \mathrm{~b}$ \\
D & $398 \mathrm{c}$ \\
E & $495 \mathrm{~d}$ \\
F & $395 \mathrm{c}$ \\
\hline
\end{tabular}

Keterangan : - Angka rata-rata yang diikuti oleh huruf yang sama menunjukkan hasil yang tidak berbeda nyata menurut Uji Jarak Berganda Duncan pada taraf $5 \%$.

- MST = Minggu Setelah Tanam

Berdasarkan uraian di awal diketahui bahwa pemberian kombinasi pupuk kandang ayam dengan pupuk urea berpengaruh baik terhadap pertumbuhan dan hasil bawang daun varietas Linda. Pengaruh baik tersebut dapat dilihat pada peningkatan tinggi tanaman, jumlah anakan, bobot dan hasil per tanaman.

Soetedjo (1993) menyatakan bahwa pemberian pupuk yang sesuai dengan dosis akan memberikan pengaruh yang baik 
terhadap pertumbuhan tanaman. Dengan demikian, kombinasi pupuk kandang ayam dan pupuk urea harus memperhatikan dosis pupuk karena dosis yang terlalu sedikit akan menyebabkan tanaman bawang daun kekurangan unsur hara $\mathrm{N}$ sehingga daun tanaman bawang daun akan menguning seperti terbakar dan akhirnya mati kering. Lebih lanjut ditegaskan oleh Lingga dan Marsono (2003), apabila dosis berlebihan akan menjadi racun bagi tanaman, sebaliknya bila kekurangan pertumbuhan tanaman tidak mengalami perubahan. Selanjutnya oleh Novizan (2002) menyatakan bahwa pemupukan yang efisien adalah pemupukan yang berfungsi menambah unsur hara yang tersedia dalam jumlah yang sedikit di dalam tanah. Dampak pemupukan yang efisien akan terlihat pada pertumbuhan tanaman yang optimal dan keuntungan usaha tani yang baik dan menguntungkan.

Dengan demikian pemupukan menggunakan kombinasi pupuk kandang ayam dan urea merupakan salah satu cara untuk memperbaiki kesuburan tanah dan juga melengkapi unsur hara yang tersedia dalam tanah sehingga tanaman mendapatkan unsur hara yang cukup bagi pertumbuhannya.

\section{KESIMPULAN}

Berdasarkan hasil analisis yang telah dilakukan maka dapat ditarik kesimpulan, yaitu :

1. Pemberian kombinasi dosis pupuk kandang ayam dan pupuk urea dengan dosis yang berbeda berpengaruh yang berbeda terhadap pertumbuhan dan hasil tanaman bawang daun varietas Linda.
2. Pemberian dosis $16 \mathrm{~g}$ pupuk kandang ayam dan 1,6 g pupuk ureamemberikan pengaruh yang paling baik terhadap pertumbuhan tinggi tanaman, jumlah anakan, dan hasil per tanaman bawang daun varietas Linda.

\section{DAFTAR PUSTAKA}

BPS. 2013. Luasan Areal,Produksi dan Produktivitas Bawang Daun Jawa Barat 2013. http://www.badanpusatstatistik/b awangdaun. (Diakses 05 maret 2014 01:02)

Laude, S dan Y. Tambing. 2010. "Pertumbuhan dan hasil bawang daun (Allium fistulosum L.) pada Berbagai Dosis Pupuk Kandang Ayam". Jurnal Agroland Vol.17 No.2

Lingga, Pinus dan Marsono. 2003. Petunjuk Penggunaan Pupuk. Penebar Swadaya. Jakarta.

Novizan. 2002. Petunjuk Pemupukan yang Efektif. Agro Medya Pustaka.

Oldeman, L.R.. (1975) an Agroclimatic Map of Java. Central Reseach Institute for Agricuture. Bogor.

Soetedjo, Mul Mulyani. 1993. Pupuk dan Cara Pemupukan. Bina Angkasa Jakarta.

Susantidiana. 2011. Jurnal Penelitian Dosis Pupuk Urea Terhadap Pertumbuhan Tanaman Bawang Daun. 